Arutyun W. Amalian, Ph.D. in Economics, Financial Director of the „Optima trading, LLC” (Kyiv, Ukraine)

Nataly D. Amalyan, Ph.D. in Economics, Assistant Professor, Ukrainian-American Concordia University (Kyiv, Ukraine)

\title{
CROWDFUNDING AND THE MYTH OF DISINTERMEDIATION
}

\begin{abstract}
Most commonly crowdfunding (peer-to-peer and peer-to-business lending in particular) is classified as a new phenomenon in financial market, which come within the equally new aggregates of 'sharing economy' and/or 'disruptive innovation' and/or 'FinTech'. More rarely it is presented as an example of ongoing process of disintermediation - disposal of a middleman between lenders and borrowers. This article is an attempt to substantiate several theses: (i) that primary financial instruments issued by debt-based crowdfunding platforms, bearing strong resemblance used in Islamic banking Mudaraba and Musharaka contracts, is nothing new in the world of finance; (ii) that more sophisticated instruments, created by crowdfunding platforms, give grounds to qualify this business model as a component of shadow banking; (iii) that contrary to the popular statement that 'peer-to-peer lending cuts the institutional "middle man" and reduce costs, in reality crowdfunding platforms do not provide any sizeable reduction of borrowing costs and, per contra, contribute to the strengthening and expansion of the banking system.
\end{abstract}

Keywords: disintermediation, sharing economy, disruptive innovations, FinTech, Islamic banking.

Nowadays the phenomenon 'crowdfunding' is a very topical subject: it attracts attention of potential lenders and is a daydream for start-ups. It is also numbers in statistics: $\$ 34$ billion raised through crowdfunding platforms, 270000 jobs created by crowdfunding and $\$ 65$ billion added to the global economy in 2017 [Crowdfunding Statistics, 2017]. It is no surprise that this practice has already become a subject of research in academic literature and a topic of debate in tabloids. Some of them endeavour to categorize this business model.

Google search for word combination 'disintermediation' and 'crowdfunding' provides about thirty six thousand matches, while concurrency of the term crowdfunding with 'sharing economy' is detected in 2290000 sources, with 'disruptive innovation' - 842000 , and with 'FinTech' - 4000 000. Vast majority of the sources are grounded on the idea that debt-based 
crowdfunding can be interpreted as an evidence of ongoing process of disintermediation and is an example of 'direct finance'.

The main objective of the paper is to analyze business model of crowdfunding (and peer-to-peer lending in particular) next to other comparable business models and to substantiate the need of the revision of traditional interpretation of crowdfunding as a way of "cutting the institutional middle man'.

The article does not contain special section for reviewing related literature - instead views of experts as well as findings of special task groups of international banking and audit organizations are presented in passages corresponding to discussed problems.

\section{Research results}

To classify any phenomenon one has to define precisely its meaning.

The most popular aggregation of crowdfunding is with FinTech. „FinTech is a new financial industry that applies technology to improve financial activities” [Schueffel, P., 2016] - this definition was provided by Patrick Schueffel in 2016 following his comprehensive scientific study of more than 200 scholarly articles on the definition of FinTech. In the same paper the author stressed that "the word "new" is inherently hard to elucidate in this context". Experts of Pricewaterhouse-Coopers Eugenie Krijnsen and Jan Willem Velthuijsen in their Executive summary "Blurred lines: How FinTech is shaping Financial Services" add to this definition additional clarifications, stating that "FinTech is shifting the paradigm of traditional intermediary roles by making them obsolete" and that "FinTech is slashing costs and improving service delivery". They evaluated cost reduction at 77\% [Krijnsen and Velthuijsen, 2016].

This mandatory characteristic of FinTech, to our opinion, can play key role over the course of categorization of debt-based crowdfunding.

Both in academic articles and in tabloids FinTech is tightly bound to disruptive innovations. This term, introduced by Harvard professor Clayton M. Christensen in 1995, is attributed to an innovation that creates a new market and value network and eventually disrupts an existing market and value network, displacing established market-leading firms, products, and alliances [Christensen, Clayton M.]. Being asked about disruptive character of crowdfunding, the godfather of the term, after investing in 2012 into crowd-funding platform CircleUp, gave a positive answer:

"I would say that for now the areas where it has the most opportunity to disrupt is by taking root in these underserved areas that traditional financiers have traditionally found unattractive. This is a classic entry point for disruption - expand participation in the market by 
lowering cost at the low end of the market, where incumbents don't see profit opportunities. Later, as the platforms gain scale, then they may start to add scope, or may start to add later-stage funding opportunities" [Primack, D., 2012].

More categorical were Philipp Haas, Christoph Peters, Ivo Blohm and Jan Marco Leimeister, plainly stating in their report at the Thirty Sixth International Conference on Information Systems in Fort Worth in 2015: "Crowdfunding represents a disruptive innovation in the banking industry" [Haas et all, 2015].

In a speech at the OECD meeting in Paris FCA Director of Competition Mary Starks listed clear benefits of the disruptive innovation in financial markets, including, among others, 'cheaper models', 'technology changing the role of human experts' and 'easier payments' [Starks, M., 2015]. Evan Bakker titled his article "PEER-TO-PEER LENDING: How digital lending marketplaces are disrupting the predominant banking model” [Bakker, 2015].

Last in the list of the most frequent conjunction of crowdfunding is 'sharing economy' or its synonyms: mesh, collaborative, peer, un-demand, gig, freelance, peer, crowd, access, platform, digital economy and collaborative consumption.

Experts of consulting firm Chappuis Halder \& Co. label LendingClub as 'a classic example of the emerging sharing economy' [What is LendingClub, 2016]. Global awardwinning public speaker Benita Matofska, the Founder and CEO and Director of Compare and Share limited (the company delivering the technology that makes a Sharing Economy possible) entitled her article "Crowdfunding is fueling growth of the Sharing Economy". Benita Matofska defines the sharing economy as "a socio-economic ecosystem built around the sharing of human, physical and intellectual resources... A Sharing Economy enables different forms of value exchange and is a hybrid economy. It encompasses the following aspects: swapping, exchanging, collective purchasing, collaborative consumption, shared ownership, shared value, co-operatives, co-creation, recycling, upcycling, re-distribution, trading used goods, renting, borrowing, lending, subscription based models, peer-to-peer, collaborative economy, circular economy, on-demand economy, gig economy, crowd economy, pay-as-you-use economy, wikinomics, peer-to-peer lending, micro financing, micro-entrepreneurship, social media, the Mesh, social enterprise, futurology, crowdfunding, crowdsourcing, cradle-to-cradle, open source, open data, user generated content (UGC) and public services" [Matofska, B. 2016].

Global thought leader on collaboration and sharing Rachel Botsman defines sharing economy as "an economic model based on sharing underutilized assets from spaces to skills to stuff for monetary or non-monetary benefits. It is currently largely talked about in relation 
to P2P marketplaces but equal opportunity lies in the B2C models" [Botsman, R., 2013], P2P marketplaces being one of the versions of crowdfunding.

The term 'crowdfunding' is used in many contexts and has many meanings depending on the source. Lambert and Schwienbacher, in particular, define crowdfunding as "an open call... for the provision of financial resources either in form of donation or in exchange for some form of reward and/or voting rights in order to support initiatives for specific purposes" [Lambert, T., Schwienbacher, A., 2010].

In business literature crowdfunding is a catch-all term for many different financial activities, including donation based, reward based, pre-sales based, equity based and lending based crowdfunding. Donation based and reward based crowdfunding do not imply financial return on investment (with donation based crowdfunding bearing strong resemblance to the philanthropy, backed by IT), and thus can be justly considered to be a variety of 'shared economy'. While pre-sales based is one of the most cheap and effective way of marketing, the last two types of crowdfunding can be interpreted as an investment activities both for the investor and for the platform. The subject of this paper is lending based crowdfunding.

Debt-based crowdfunding (P2Plending or loan marketplace is often interpreted as a quite a new form of direct financing subject to condition that the lenders and borrowers usually do not know each other. This model is used by borrowers who either are looking for a loan with a lower interest rate than the one they can get from a bank, or those that have no access to banks' credits or those, who can offer fewer securities. In popular perception P2P, B2C, P2B lending are examples of sharing economy, with FinTech disrupting traditional banking, eliminating 'the middleman'.

To examine reliability of these views it would be expedient to study business model of the world's largest peer-to-peer lending platform - LendingClub. This company was launched in May 2007 on Facebook as one of Facebook's first applications, and in seven years it became public, completing its $\$ 900$ million IPO in December 2014.

Nowadays LendingClub proposes to different kinds of lenders different ways of investments (and correspondingly, different financial instruments).

For retail investors meeting the applicable financial suitability requirements LendingClub offers unsecured, borrower payment dependent notes that correspond to payments received on an underlying standard program loan selected by the investor. These securities are titled 'promissory notes', by which the borrowers promise "to pay to the order of WebBank or any subsequent holder ... of this Note the principal sum ... with interest” [Borrower Agreement, 2018]. 
As provisions of the LendingClub Borrower Agreement demonstrate, money collected from the lenders (imagining that they 'in crowd' are funding some specific project through the LendingClub platform), in reality is used to buy a loan from WebBank. WebBank is FDIC-insured, state-chartered Industrial Bank organized under the laws of the State of Utah, which is the company's origination partner.

By the term of current lending model, the loans are divided into the notes. WebBank endorses the notes to LendingClub, and LendingClub then assigns each note to the respective lender members. Borrowers enter into a loan agreement with WebBank. WebBank processes the loans, manages the money coming in from the lender members to fund the loans, and remits the monies to the corresponding borrower members [LendingClub Consumer Finance, 2011].

According to the terms of LendingClub's August 22, 2014 Prospectus for the issue of its promissory notes, LendingClub's "obligation to make payments on a Note will be limited to an amount equal to the investor's pro rata share of amounts we receive with respect to the corresponding member loan for that Note, net of our $1.00 \%$ service charge. We do not guarantee payment of the Notes or the corresponding member loans, and the Notes are not obligations of our borrower members... If we were to become subject to a bankruptcy or similar proceeding, the rights of the holders of the Notes could be uncertain, and payments on the Notes may be limited and suspended or stopped... Because a bankruptcy or similar proceeding may take months or years to complete, the suspension of payment may effectively reduce the value of any recovery that a holder of a Note may receive (and no such recovery can be assured) by the time any recovery is available... The Notes are unsecured and holders of the Notes do not have a security interest in the corresponding Loans or the proceeds of those corresponding Loans" [LendingClub, 2014].

Much more sophisticated model is used while dealing with institutional investors: for them LendingClub sponsors securitization transactions ${ }^{1}$ backed by loans facilitated through its platform. Upon securitization program LendingClub's acts as Sponsor, Servicer and Administrator. The inaugural $\$ 279$ million deal, backed exclusively by subprime consumer loans, was closed in summer 2017 [Bisbey, A., 2017].

In December 2017 LendingClub introduced a whole loan transaction structured as a tradeable, pass-through security called a CLUB Certificate (Certificate of the Consumer Loan Underlying Bond). A pass-through security is a derivative based on certain debt receivables and providing the investor a right to a portion of those profits. Often, the debt receivables

1 Securitization is the procedure whereby an issuer designs a financial instrument by merging various financial assets and then markets tiers of the repackaged instruments to investors. 
are from underlying assets, which can include things such as mortgages on homes or loans on vehicles. Each security represents a large number of debts, such as hundreds of homes or thousands of cars. Unlike a securitization, the certificates only pool 3 years or 5 years loans of a particular grade that the investor is looking for.

CLUB certificates (available only for qualified institutional buyers), which were issued by the Trust, are unsecured and settled with cash flows from underlying loans selected by the investor. The CLUB Certificates - an initiative that was investor led - are tailored for an institutional investor seeking a liquid vehicle with which to access the consumer credit asset class. What this investor wanted was a security that acted like a whole loan but one that had liquidity.

Investors can trade the certificates with a CUSIP ${ }^{2}$ numbers over the counter by clearing through The Depository Trust \& Clearing Corporation.

For borrowers LendingClub propose term loans (12 - 60 months) to the amount of $\$ 1000$ - \$300 000. Rates vary from 5,32\% to $28,99 \%$ [LendingClub sites].

LendingClub day-to-day activity includes screening borrowers, facilitating transaction, servicing the loans and interest rate determination.

Until its recent disclosure, LendingClub calculated interest rates based on a borrower's FICO score, debt-to-income (DTI) ratio, and amount borrowed. In its Amended S-1, LendingClub disclosed that under a new formula, it started to use several other credit markers in calculating interest rates. Specifically, LendingClub now factors in a borrower's number of open accounts, the number of credit inquiries in the last six months, how much of a borrower's available credit is used up, and length of credit history [Berger R., 2012].

On the basis of the abovementioned and other data, LendingClub assigns a grade to each borrower. The credit grades range from A to $\mathrm{G}$, and each letter grade has a sub-grade ranging from 1 to 5 . An uniform base rate $(5,05 \%)$ is set for all the grades; it is added for specific for client's grade and sub-grade adjustment for risk and volatility (starting from $0,27 \%$ and up to $23,94 \%$ ). Derived sum became turns into specific for each borrower interest rate, that can vary from 5,32\% (grade A, sub-grade 1) to 28,99\% (grade G, sub-grade 5).

Speaking about rates (which are commonly believed to be lower than in banks) it is worth to mention a court action against Lending Club and WebBank, in which the plaintiff Ronald Bethune filed the complaint in April 2016, challenging a loan obtained through Lending Club's online platform and issued by WebBank. The plaintiff alleged, on behalf of himself and other similarly situated individuals, that the defendants violated state usury laws, state 2 Committee on Uniform Securities Identification Procedures 
consumer protection laws, and the federal Racketeer Influenced and Corrupt Organizations Act by lending to borrowers at interest rates above the usury caps in the borrowers' home states [US District court, 2017].

\section{Conclusions}

Analysis of LendingClub financials qualifies for three deductions:

1. Lending-based crowdfunding in its economic essence is nothing new. By its economic essence promissory notes, issued to the lenders, can be interpreted as an example of successful infiltration of traditional Islamic banking into Western style of lending.

The closest analogue of primary debt securities of crowdfunding platform, in our opinion, is risk-sharing instruments in Islamic financial and economic system. In Islamic banks depositors earn dividends when the peer borrower makes a profit and lose part of their savings if the borrower fails - contrary to our traditional banking model, based on 'deposit-taking activity in respect to the funds of individuals and legal entities, placement of these funds on its own behalf, own conditions and at its own risk'.

On the asset side, Islamic banks engage in investment and trading activities according to the various contracts available. On the deposit side, funds are mainly mobilized on the basis of a Mudaraba or Musharaka contracts.

A Mudaraba contract is based on a partnership in which one partner is the financier (the investor, or silent partner) and the other partner (the fund manager, or working partner) manages the financier's investment in an economic activity. In this contract, the basic factors of production (from the Islamic economics viewpoint) - capital, labor, and entrepreneurship are combined to make an economic activity. Both parties agree in advance to a profit and loss sharing (PLS) ratio. The working partner also receives a fixed fee for managing the project, in addition to a share of any profits. All Mudaraba contracts are limited by a specific time period; they can't continue indefinitely.

A Musharaka contract is an agreement where two or more parties (for example an Islamic bank and its clients) agree to contribute to the capital - in cash or in kind, no debt is accepted - of the partnership in equal or varying amounts to establish a new project or share in an existing one. Musharaka partners must share profit and loss.

In essence these instruments bear strong resemblance to the primary tools of debt-based crowdfunding.

Summarizing review of debt-based crowdfunding, the officer of Federal Reserve Bank of San Francisco Ian J. Galloway claimed that P2P "lending" is somewhat of a misno- 
mer. In fact, no platform allows lenders to lend directly to borrowers. Platforms either: (1) broker loan reimbursements through interest-free investments; (2) broker the sale of securities backed by their issuers; or (3) facilitate the origination of loans which are sold as securities to P2P investors who behave like lenders (and who may not even realize the nuance) [Galloway, I., 2009].

To destroy the myth of direct P2P or P2B lending for good and all here are financial results of LendingClub activities:

In 2017 LendingClub transaction fees exceeded \$448,6 million, investor fees $\$ 87,1$ million and interest income - \$611 million (with interest expense over $\$ 571$ million). Total net revenue of the company in the same year ran up to $\$ 574$ million.

2. Analysis of the more sophisticated instruments, created by crowdfunding platforms (Securitization securities, Whole Loan Purchases and CLUB Certificates) proposed only to qualified institutional investors, allows to assert that the biggest crowdfunding platforms are taking a new life as an ingredient of shadow banking. The UK's Financial Conduct Authority (FCA) in its findings in 2016 stated, that several crowdfunding companies "were found to have given preferential treatment to lucrative institutional investors at the expense of others" [Financial Conduct Authority, 2016]. Kroll Bond Rating Agency indicates that in 2017 lending platforms issuance of asset backed securities in 2017 topped $\$ 7.8$ billion, up from $\$ 4.6$ billion in 2016, a year over year increase of 71\% [KBRA, 2018].

In literature at present it is debatable whether peer-to-peer lending can even be considered crowdfunding anymore, as the platforms have been hugely successful, eclipsing the rest of the crowdfunding industry in size, and have brought in lots of money from financial institutions, rather than relying on the crowd to make small investments. [Top Investment Crowdfunding Portals]

Investors base of LendingClub at the beginning of 2017 shows, that while the share of retail investors was $13 \%$, banks share came to $31 \%$ and money managers - $43 \%$ [Bisbey, A., 2017].

3. Contrary to the popular statement that "peer-to-peer lending cuts the institutional "middle man" and costs, allowing lenders to choose an investment themselves and entrepreneurs to benefit from lower interest rates, in reality crowdfunding platforms per contra, contribute to the strengthening and expansion of the banking system and do not provide any sizeable reduction of borrowing costs. All the debt-based platform charge percentage fee of the money raised, while some of them additionally charge for software subscription services and other 
services, including marketing, campaign management, PR outreach, prototype development, design and branding etc. In total, average revenue of the platform for a loan generated via LendingClub is $\$ 850$ [Investor Day, 2017]

Analysis of the LendingClub financials demonstrates that at bottom of fact, crowdfunding platforms act as an additional intermediary link in between lenders and borrowers, making process of money lending more complex.

\section{Bibliography}

1. Bakker, Evan. PEER-TO-PEER LENDING: How digital lending marketplaces are disrupting the predominant banking model. BUSINESS INSIDER. Jun. 23, 2015. Available on line: https:/www.businessinsider.com/peer-to-peer-lending-how-digitallending-marketplaces-are-disrupting-the-predominant-banking-model-2015-5

2. Berger Rob. LendingClub Files Amended S-1 and Discloses Changes to How it Sets Interest Rates March 22, 2012. Available on line: https://www.doughroller.net/ p2p-lending/lendingclub-changes-how-it-sets-interest-rates/

3. Bisbey, Allison Club deal LendingCLub's rst self-sponsored ABS makes it less beholden to direct loan buyers. Aseet Securitization Report, July / August 2017, p.7. Available on line: https://assets.sourcemedia.com/03/15/786307f44a8eb7ecf30668adcecf/asr070817.pdf

4. Botsman, R. The sharing economy lacks a shared definition, Co.Exists, 21 November, 2013. Available on line: http://www.fastcoexist.com/3022028/the-sharing-economy-lacksa-shared-definition\#4

5. Christensen, Clayton M. Disruptive innovations. Official website of Clayton M. Christensen. Available on line: http://www.claytonchristensen.com/key-concepts/

6. KBRA. 2017 Consumer loan marketplace lending year in review and 2018 outlook. Kroll Bond Rating Agency, Inc., 2018. Available on line: https://lending-times.com/wp-content/ uploads/2018/01/KBRA-consumer-loan-mpl-abs-report-2017.pdf

7. Crowdfunding Statistics [Updated for 2017!]. Official website of FUNDLY. Available on line: https://blog.fundly.com/crowdfunding-statistics/

8. Disruptive innovation in financial markets. Speech by Mary Starks. Official site of the FCA, 26.10.2015. Available on line: https://www.fca.org.uk/news/speeches/disruptiveinnovation-financial-markets

9. Financial Conduct Authority to crack down on crowdfunding. December 12, 2016. Official site of Business Insider. Available on line: https:/www.businessinsider.com/financialconduct-authority-to-crack-down-on-crowdfunding-2016-12

10. Haas, P., Peters C., Blohm I., Leimeister, J. M. Modularization of Crowdfunding Services - Designing Disruptive Innovations in the Banking Industry Thirty Sixth International Conference on Information Systems, Fort Worth 2015 Conference Paper. Available on line: 
https://www.researchgate.net/figure/Crowdfunding-Service-Ecosystem_fig1_283045422

11. Harvard Law School MEMORANDUM Case Study: Lending Club Consumer Finance, Spring 2011. Available on line: https://wiki.harvard.edu/.../CSP\%20028\%20Lending\%20 Club\%2008.31.17_v4.pdf

12. Investor Day Presentation. LendingClub December 7, 2017. Available on line: https:// seekingalpha.com/article/4130669-lendingclub-lc-investor-presentation-slideshow

13. Krijnsen, Eugenie and Velthuijsen, Jan Willem. "Blurred lines: How FinTech is shaping Financial Services" Retrieved from pwc.com/fintechreport. 2016, pp. 6, 9. Available on line: https://www.pwc.nl/nl/assets/documents/pwc-how-fintech-is-shaping-financialservices.pdf

14. Lambert, T. and Schwienbacher, A. An Empirical Analysis of Crowdfunding. Mimeo. 2010

15. LendingClub. Borrower Agreement. Exhibit A. LOAN AGREEMENT AND PROMISSORY NOTE. Official website of LendingClub. Available on line: https://www.lendingclub.com/info/borrower-agreement.action

16. LendingClub. Member Payment Dependent Notes: Prospectus. Available on line: https:// www.sec.gov/Archives/edgar/data/1409970/000119312514319072/d775378ds3asr.htm

17. Matofska, Benita. What is the Sharing Economy? Official site of "The People Who Share" September 1, 2016. Available on line: http://www.thepeoplewhoshare.com/blog/what-isthe-sharing-economy/

18. Primack, Dan Exclusive: Clayton Christensen gets into crowdfunding / Fortune. June 13, 2012. Available on line: http://fortune.com/2012/06/13/exclusive-clayton-christensen-getsinto-crowdfunding/

19. Schueffel, Patrick. Taming the Beast: A Scientific Definition of Fintech. Journal of Innovation Management. JIM 4, 4 (2016), p. 45. Available on line: https://hesso.tind.io/ record/1996/files/Schueffel_Tamingthebeast_2016.pdf https://doi.org/10.24840/2183-0606_004.004_0004

20. Top Investment Crowdfunding Portals. Info and news site CrowdExpert.com. Available on line: http://crowdexpert.com/investment-crowdfunding-platform-directory/

21. UNITED STATES DISTRICT COURT. SOUTHERN DISTRICT OF NEW YORK Case 1:16-cv-02578-NRB Document 46 Filed 01/30/17. Available on line: https://www. hudsoncook.com/alerts/alerts_02022017030238_654.pdf

22. What is LendingClub all about? Official site of Fintank. May 14, 2016. Available on line: http://fintank.net/newsletter/lendingclub-p2p/ 